\title{
Pengembangan Alat Ukur Tingkat Efikasi Diri Siswa dalam Pembelajaran Kimia
}

\author{
Febrian Solikhin \\ Program Studi Pendidikan Kimia, Universitas Bengkulu, Indonesia \\ febrian.solikhin@unib.ac.id
}

\begin{abstract}
This study aims to develop a student self-efficacy scale in learning, especially in chemistry learning. This scale has been developed with 4 main steps, namely the determination of aspects, preparation of indicators, preparation of statement items and validation. The measured aspects are activity choice, effort, perseverance, learning, achievement, and strategy orientation. The items developed were 30 statements. The validation process consists of expert validation and empirical validation. At the expert validation produced 24 valid statement points viewed from the Aiken $V$. The empirical validation phase involved 300 high school students. Analysis of the results at this stage using the Rasch model. At this stage, there were 22 valid and reliable statements for use in measuring students' level of self-efficacy.
\end{abstract}

Keywords. chemistry learning; self-efficacy; scale

\begin{abstract}
Abstrak
Penelitian ini bertujuan untuk mengembangkan alat ukur efikasi diri siswa dalam pembelajaran, khususnya dalam pembelajaran kimia. Alat ukur ini telah dikembangkan dengan 4 langkah utama, yaitu penentuan aspek, penyusunan indikator, penyusunan butir pernyataan dan validasi. Aspek yang diukur adalah pilihan aktivitas, usaha, ketekunan, belajar, pencapaian/prestasi, dan orientasi strategi. Butir yang dikembangkan sebanyak 30 pernyataan. Proses validasi terdiri atas validasi ahli dan validasi empiris. Pada tahap validasi ahli menghasilkan 24 butir pernyataan valid dilihat dari besar Aiken V. Tahap validasi empiris melibatkan 300 siswa SMA. Analisis hasil pada tahap menggunakan model Rasch. Pada tahap ini menghasilkan sebanyak 22 butir pernyataan valid dan reliabel untuk digunakan dalam pengukuran tingkat efikasi diri siswa.
\end{abstract}

Kata Kunci: alat ukur; efikasi diri; pembelajaran kimia 


\section{Pendahuluan}

Pembelajaran merupakan proses komunikasi dua arah antara siswa dengan guru. Pembelajaran memiliki target yang terarah antara peserta didik dan guru yang telah ditentukan sebelumnya (Trianto, 2009). Pembelajaran ditandai adanya proses belajar. Belajar sendiri merupakan proses perubahan yang dilakukan oleh manusia itu sendiri dengan tujuan mendapatkan kompetensi, sikap dan keterampilan (Baharudin \& Wahyuni, 2009). Pernyataan tersebut membuktikan bahwa tanda seseorang telah melakukan belajar adalah adanya perubahan, baik dari perubahan tingkah laku, perubahan pengetahuan, atau perubahan sikap. Perubahan ini diharapkan perubahan dari segi kebaikan. Proses belajar dilakukan manusia sejak dari masih bayi hingga seseorang tersebut meninggal dunia (Sadiman et al., 1984). Belajar tidak harus dilakukan di sekolah, namun belajar dapat dilakukan dimana saja, kapan saja, dan oleh siapa saja. Dimana saja bisa dijadikan sebagai sekolah, kapan pun bisa dijadikan waktu belajar, dan siapapun bisa menjadi seorang guru.

Dalam pembelajaran di sekolah, tak lepas dengan adanya kurikulum. Kurikulum merupakan seperangkat aturan yang dibuat dalam proses pembelajaran yang akan dilakukan. Kurikulum ini berisi rencana yang sistematis dalam sekolah mencapai tujuan yang telah ditentukan (Arifin, 2013; Ornstein \& Hunkins, 2009). Saat ini di Indonesia menggunakan Kurikulum 2013 yang membutuhkan siswa aktif dalam proses pembelajarannya. Kurikulum ini terdapat standar kompetensi lulusan, standar isi, standar proses dan standar penilaian sebagai standar utama. Standar penilaian terdapat 3 aspek utama yang dinilai dalam proses pembelajarannya. Ketiga aspek ini adalah pengetahuan/kognitif, sikap/afektif, dan keterampilan/psikomotor.

Efikasi diri merupakan salah satu sikap yang dapat dikembangkan dalam proses pembelajaran di sekolah. Efikasi diri merupakan kepercayaan yang dimiliki seseorang yang berhubungan dengan kemampuan dirinya sendiri dalam suatu kegiatan. Efikasi diri berhubungan dengan kemampuan pribadi siswa dalam mengolah sesuatu (Woolfolk, 2007). Menurut (Bandura, 1994) keyakinan semacam ini menghasilkan proses kognitif, proses motivasi, proses afektif, dan proses seleksi. Proses kognitif berhubungan dengan proses menangkap pengetahuan, proses motivasi berhubungan dengan motivasi diri dalam melakukan sesuatu, proses afektif berhubungan sikap, dan proses seleksi adalah berhubungan memilih sesuatu sesuai kehendaknya.

Efikasi diri ini akan berpengaruh terhadap proses belajar dan aktivitas seseorang di sekolah. Efikasi diri ini dapat membuat seseorang yakin dalam mengolah kelakuannya (Ormrod, 2003). Dalam pembelajaran, khususnya pembelajaran kimia, efikasi diri menjadi salah satu unsur instrinsik yang penting. Efikasi diri ini dapat mempengaruhi prestasi akademik seorang siswa. Efikasi diri dan prestasi akademik memiliki hubungan yang positif saat pembelajaran kimia berlangsung (Kolo et al., 2017). Pencapaian belajar siswa dengan efikasi diri yang tinggi akan lebih baik daripada siswa dengan kemampuan yang sama namun memiliki efikasi diri yang lebih rendah (Zimmerman et al., 1992).

Dimensi efikasi diri sebanyak 3 (tiga), yaitu tingkat (level), keluasan (generality), dan kekuatan (strength) (Bandura, 1997). Dimensi tingkat berhubungan dengan tingkat kesulitas aktivitas belajar. Dimensi keluasan berhubungan dengan penguasaan terhadap suatu tugas tertentu. Sedangkan dimensi kekuatan berhubungan pada tingkat kekuatan dan kemantapan individu. Ketiga dimensi ini juga dapat diamati dalam proses pembelajaran.

Penelitian ini bertujuan untuk mengembangkan alat ukur efikasi diri siswa dalam pembelajaran kimia. Beberapa penelitian sebelumnya telah melakukan pengembangan alat ini ukur ini. Namun, kebanyakan alat ukur digunakan untuk mengukur efikasi diri mahasiswa dalam suatu perkuliahan. Untuk itu dilakukan pengembangan alat ukur untuk siswa ini dengan mengembangkan dari aspek-aspek sederhana yang berhubungan dengan kegiatan siswa dalam pembelajaran. 


\section{Metode}

Pengembangan alat ukur efikasi diri ini menggunakan 4 (empat) langkah utama. Langkah pertama yaitu penentuan aspek. Penentuan aspek melalui telaah berbagai sumber, mulai dari buku hingga artikel jurnal. Aspek yang digunakan dalam mengembangkan aspek ini ada 6 (enam) aspek, yaitu pilihan aktivitas, usaha, ketekunan, belajar, pencapaian, dan orientasi strategi (Dinther et al., 20II; Kurbanoglu \& Akim, 20I0; Ormrod, 2003; Santrock, 20II; Zimmerman et al., 1992). Keenam aspek tersebut digunakan untuk menentukan indikator dalam mengukur efikasi diri seseorang. Indikator itu kemudian digunakan untuk mengembangan butir pernyataan. Butir pernyataan yang dikembangkan sebanyak 30 butir. Langkah selanjutnya adalah tahap validasi. Tahap ini terbagi menjadi 2 (dua), yaitu validasi teori dan validasi empiris. Validasi teori dilakukan oleh ahli yang berasal dari jurusan psikologi. Analisis hasil validasi ahli ini menggunakan analisis $\mathrm{V}$ Aiken untuk setiap butir pernyataan. Validasi teori digunakan untuk mengukur validitas masing-masing butir menurut pernyataan ahli. Persamaan yang digunakan dalam analisis ini adalah (Aiken, 1985).

$$
V=\frac{\sum s}{[n(c-1)]}
$$

Catatan: $\mathrm{s}=\mathrm{r}-\mathrm{lo} ; \mathrm{r}=$ skor dari ahli; lo $=$ skor minimum validasi; $\mathrm{n}=$ jumlah ahli; $\mathrm{c}=$ jumlah kategori

Kriteria yang digunakan dalam validasi teori ini adalah skor I untuk not necessary (tidak perlu), skor 2 untuk useful but not essential (berguna tapi tidak penting), dan skor 3 untuk essential (penting) (Lawshe, I975). Ahli yang digunakan dalam validasi ini adalah sebanyak 4 Ahli. Jika keempat ahli memberikan skor 3 untuk suatu butir penilaian, maka perhitungan besar $\mathrm{V}$ Aiken sebagai berikut.

$$
V=\frac{(3-1)+(3-1)+(3-1)+(3-1)}{[4 *(3-1)]}=1
$$

Dengan ahli sejumlah 4 dan kategori skor sebanyak 3, V Aiken tabel diperoleh adalah I,00 dengan righttail probabilities 0,0I2 (Aiken, I985). Jika V Aiken hitung kurang dari I,00, maka butir pernyataan tersebut dinyatakan tidak valid berdasarkan validitas teori.

Validasi empiris melibatkan 300 siswa SMA kelas XI dari beberapa sekolah di Daerah Istimewa Yogyakarta yang dipilih secara random. Mereka terdiri dari 38,7\% siswa laki-laki dan 6I,3\% siswa perempuan dengan rentang umur I6-I8 tahun. Hasil validasi empiris ini kemudian dianalisis menggunakan Rasch model untuk mengetahui butir pernyataan yang valid dan reliabel serta dapat digunakan dalam proses pengukuran tingkat efikasi diri siswa dalam pembelajaran. Model perhitungan Rasch ini memiliki kemiripan dengan teori respons butir (IRT) I PL karena melibatkan I parameter, yaitu tingkat kesulitan butir, namun keduanya tetap dipandang sebagai model pengukuran yang berbeda (Sumintono \& Widhiarso, 2015). Dalam penelitian ini, pengujian validitas dan reliabilitas instrumen menggunakan program Quest, sehingga besar validitas dan reliabilitas langsung dapat diketahui dari output program tersebut. Sebuah butir pernyataan dikatakan valid apabila memiliki Infit Mean Square sebesar 0,77 hingga I,30. Sedangkan untuk reliabilitas yang diterima berada pada rentang 0,70 hingga 0,95 (Tavakol \& Dennick, 20II).

\section{Hasil dan Pembahasan}

Alat ukur efikasi diri telah berhasil dikembangkan dengan baik. Efikasi diri dipengaruhi oleh berbagai aspek. Aspek-aspek ini ditentukan melalui telaah buku dan artikel jurnal dengan topik psikologi. Aspek yang telah ditentukan adalah pilihan aktivitas, usaha, ketekunan, belajar, pencapaian, dan orientasi strategi (Ormrod, 2003; Santrock, 20II). 
Pilihan aktivitas merupakan aspek pertama yang akan diukur dalam efikasi diri seseorang. Aktivitasaktivitas yang dipilih orang seseorang, khususnya dalam pembelajaran akan mempengaruhi tingkat efikasi dirinya. Seseorang dengan tingkat efikasi diri yang tinggi, akan memilih tugas atau aktivitas pembelajaran yang menantang dan sulit. Namun, mereka yakin dapat menyelesaikan tugas atau aktivitas tersebut dengan baik. Begitu sebaliknya, tugas atau aktivitas tersebut dihindari oleh seseorang dengan tingkat efikasi diri yang rendah. Mereka tidak yakin dapat menyelesaikan tugas atau aktivitas tersebut (Dinther et al., 20II; Kurbanoglu \& Akim, 2010; Ormrod, 2003; Santrock, 20II; Zimmerman et al., I992). Kedua indikator tersebut kemudian dapat dikembangkan menjadi beberapa butir pernyataan.

Tabel I. Butir Pernyataan Aspek Pilihan Aktivitas

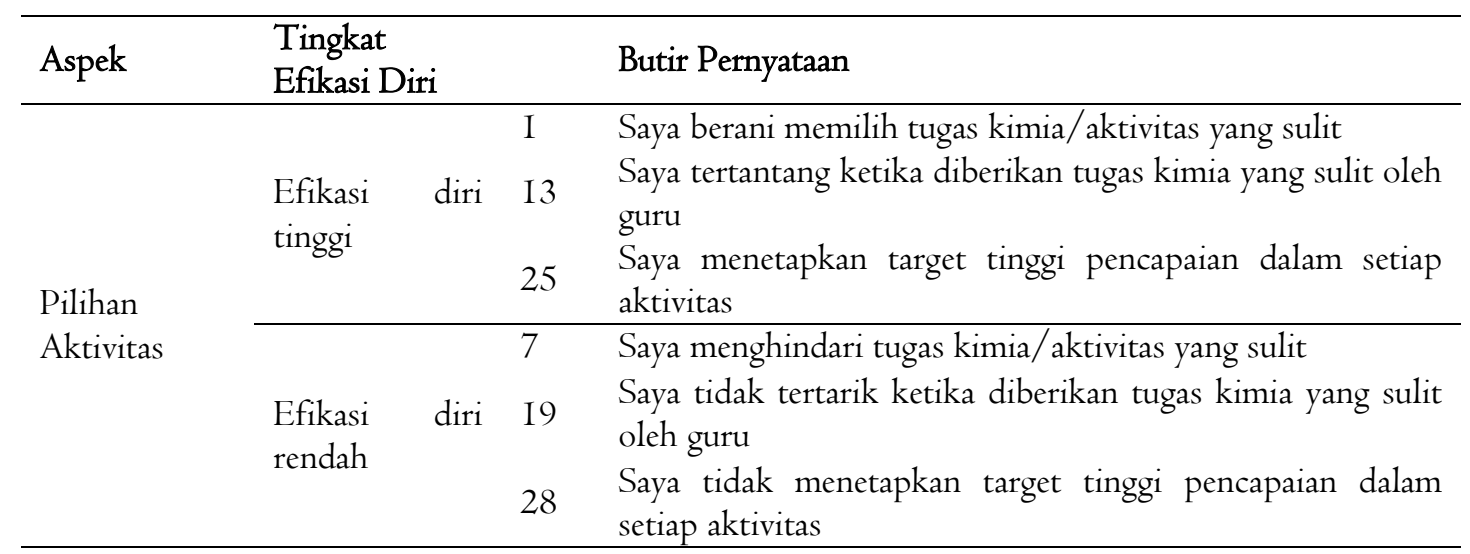

Aspek kedua yang dikembangkan adalah aspek usaha. Antara satu orang dengan orang lainnya memiliki usaha yang berbeda dalam meraih sesuatu. Begitu pula untuk orang dengan tingkat efikasi diri yang berbeda. Seseorang dengan tingkat efikasi diri yang tinggi mempunyai usaha yang besar dengan sekuat tenaga mereka untuk menyelesaikan tugas atau aktivitas yang telah mereka pilih sesuai dengan batas waktu yang disediakan. Sedangkan mereka yang mempunyai tingkat efikasi diri rendah memiliki usaha yang seadanya dalam menyelesaikan tugas atau aktivitas (Dinther et al., 20I I; Kurbanoglu \& Akim, 2010; Ormrod, 2003; Santrock, 20II; Zimmerman et al., 1992). Pengembangan butir pernyataan dengan kedua indikator tersebut dapat dilihat pada Tabel 2.

Tabel 2. Butir Pernyataan Aspek Usaha.

\begin{tabular}{|c|c|c|c|c|}
\hline Aspek & $\begin{array}{l}\text { Tingkat } \\
\text { Diri }\end{array}$ & Efikasi & & Butir Pernyataan \\
\hline \multirow[t]{2}{*}{ Usaha } & $\begin{array}{l}\text { Efikasi } \\
\text { tinggi }\end{array}$ & diri & I4 & $\begin{array}{l}\text { Saya berusaha keras dalam menyelesaikan tugas kimia } \\
\text { sesulit apapun sesuai jatuh tempo } \\
\text { Saya berusaha untuk menyelesaikan tugas kimia } \\
\text { dengan memaksimalkan waktu }\end{array}$ \\
\hline & $\begin{array}{l}\text { Efikasi } \\
\text { rendah }\end{array}$ & diri & 20 & $\begin{array}{l}\text { Saya menyelesaikan tugas kimia semampunya } \\
\text { Saya tidak memaksimalkan kemampuan saya dalam } \\
\text { menyelesaikan tugas kimia }\end{array}$ \\
\hline
\end{tabular}

Aspek selanjutnya adalah ketekunan. Ketekunan orang dengan tingkat efikasi diri tinggi jelas berbeda dengan orang dengan tingkat efikasi diri yang rendah. Efikasi diri yang tinggi mempengaruhi seseorang untuk bertahan dalam kondisi apapun, tentunya sebagai upaya menyelesaikan tugas atau melakukan aktivitas yang mereka pilih. Sedangkan efikasi diri yang rendah membuat seseorang mudah untuk menyerah dalam menghadapi kesulitan (Dinther et al., 20II; Kurbanoglu \& Akim, 20I0; Ormrod, 2003; Santrock, 20II; Zimmerman et al., 1992). Indikator tersebut dapat dikembangkan menjadi butir pernyataan dan dapat dilihat pada Tabel 3. 
Tabel 3. Butir Pernyataan Aspek Ketekunan

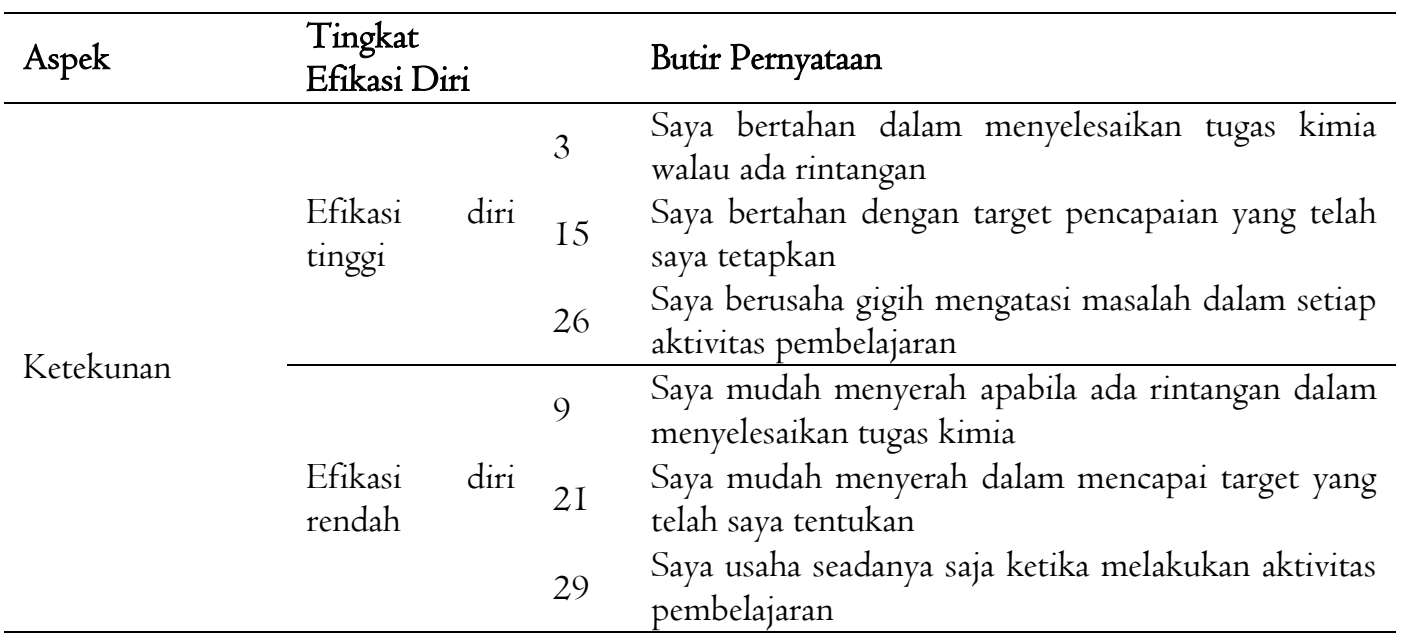

Aspek keempat adalah aspek belajar. Proses belajar seseorang akan berbeda satu sama lain. Terlebih jika tingkat efikasi diri mereka juga berbeda. Seseorang dengan efikasi diri yang tinggi pasti akan menggunakan pengalaman yang selama ini mereka alami untuk menyelesaikan tugas atau aktivitas tertentu. Pengalaman merupakan guru yang berharga. Sedangkan tingkat efikasi diri yang rendah membuat pengalaman tersebut hanya menjadi angin lalu dan tidak digunakan dalam menyelesaikan permasalahan yang ada (Kurbanoglu $\&$ Akim, 2010; Ormrod, 2003; Santrock, 20I I). Tabel 4 merupakan pengembangan butir pernyataan dari kedua indikator tersebut.

Tabel 4. Butir Pernyataan Aspek Belajar

\begin{tabular}{|c|c|c|c|}
\hline Aspek & $\begin{array}{l}\text { Tingkat } \\
\text { Efikasi Diri }\end{array}$ & & Butir Pernyataan \\
\hline \multirow{3}{*}{ Belajar } & $\begin{array}{l}\text { Efikasi } \\
\text { tinggi }\end{array}$ & 16 & $\begin{array}{l}\text { Saya memanfaatkan pengalaman yang telah saya } \\
\text { dapatkan dalam melakukan aktivitas belajar } \\
\text { Saya belajar hingga memahami materi/konsep kimia }\end{array}$ \\
\hline & \multirow{2}{*}{$\begin{array}{l}\text { Efikasi } \\
\text { rendah }\end{array}$} & IO & $\begin{array}{l}\text { Saya melakukan aktivitas belajar kimia tanpa } \\
\text { memanfaatkan pengalaman yang telah saya dapatkan }\end{array}$ \\
\hline & & 22 & $\begin{array}{l}\text { Saya belajar dengan sekilas hanya untuk } \\
\text { menyelesaikan tugas kimia }\end{array}$ \\
\hline
\end{tabular}

Aspek yang selanjutnya adalah aspek pencapaian atau prestasi. Pencapaian yang diraih oleh 2 (dua) orang berbeda tentunya akan berbeda pula. Orang dengan efikasi diri yang tinggi yakin menyelesaikan tugas dan dapat mempunyai pencapaian yang baik pula. Sedangkan orang dengan efikasi diri yang rendah ragu dalam menyelesaikan tugasnya serta memiliki pencapaian yang kurang maksimal (Kurbanoglu \& Akim, 20I0; Ormrod, 2003; Zimmerman et al., 1992). Apabila ada 2 (dua) orang dengan kemampuan yang sama, namun memiliki efikasi yang berbeda, pencapaian atau prestasinya pun juga akan berbeda (lihat Tabel 5).

Aspek terakhir yang dikembangkan adalah aspek orientasi strategi. Efikasi diri yang tinggi membuat seseorang selalu menggunakan strategi dalam memecahkan permasalahan atau menjalankan aktivitasnya. Begitupun sebaliknya, jika seseorang itu memiliki efikasi diri yang rendah maka mereka tidak akan menggunakan strategi dalam menjalankan aktivitasnya dan memecahkan permasalahan yang ada (Kurbanoglu \& Akim, 20I0; Santrock, 20II; Zimmerman et al., I992). Tabel 6 merupakan butir pernyataan yang dikembangkan menggunakan 2 (dua) indikator tersebut. 
Tabel 5. Butir Pernyataan Aspek Pencapaian/Prestasi

\begin{tabular}{|c|c|c|c|}
\hline Aspek & $\begin{array}{l}\text { Tingkat } \\
\text { Efikasi Diri }\end{array}$ & & Butir Pernyataan \\
\hline \multirow{2}{*}{ Pencapaian/ prestasi } & $\begin{array}{l}\text { Efikasi } \\
\text { tinggi }\end{array}$ & I7 & $\begin{array}{l}\text { Saya yakin dapat menyelesaikan tugas kimia tanpa } \\
\text { bantuan dari orang lain } \\
\text { Saya yakin dapat memperoleh hasil belajar kimia } \\
\text { yang memuaskan }\end{array}$ \\
\hline & $\begin{array}{l}\text { Efikasi } \\
\text { rendah }\end{array}$ & 23 & $\begin{array}{l}\text { Saya bergantung pada orang lain dalam } \\
\text { mengerjakan tugas kimia } \\
\text { Saya ragu akan mendapatkan hasil belajar kimia } \\
\text { yang memuaskan }\end{array}$ \\
\hline
\end{tabular}

Tabel 6. Butir Pernyataan Aspek Orientasi Strategi

\begin{tabular}{|c|c|c|c|c|}
\hline Aspek & $\begin{array}{l}\text { Tingkat } \\
\text { Diri }\end{array}$ & Efikasi & & Butir Pernyataan \\
\hline \multirow{6}{*}{$\begin{array}{l}\text { Orientasi } \\
\text { Strategi }\end{array}$} & \multirow{3}{*}{$\begin{array}{l}\text { Efikasi } \\
\text { tinggi }\end{array}$} & \multirow{3}{*}{ diri } & 6 & $\begin{array}{l}\text { Saya belajar dengan teratur agar memperoleh hasil yang } \\
\text { maksimal }\end{array}$ \\
\hline & & & I8 & $\begin{array}{l}\text { Saya mengerjakan tugas jauh-jauh hari agar mendapatkan } \\
\text { hasil yang memuaskan }\end{array}$ \\
\hline & & & 27 & $\begin{array}{l}\text { Saya memiliki cara belajar yang cocok agar dapat memahami } \\
\text { materi pembelajaran kimia }\end{array}$ \\
\hline & \multirow{3}{*}{$\begin{array}{l}\text { Efikasi } \\
\text { rendah }\end{array}$} & \multirow{3}{*}{ diri } & $\mathrm{I} 2$ & $\begin{array}{l}\text { Saya belajar hanya pada saat menghadapi tugas/ulangan } \\
\text { kimia }\end{array}$ \\
\hline & & & 24 & $\begin{array}{l}\text { Saya mengerjakan tugas kimia mendekati waktu } \\
\text { pengumpulan }\end{array}$ \\
\hline & & & 30 & $\begin{array}{l}\text { Saya tidak memiliki cara belajar tersendiri dalam memahami } \\
\text { materi pembelajaran kimia }\end{array}$ \\
\hline
\end{tabular}

Pengembangan butir pernyataan terdiri atas pernyataan positif dan pertanyaan negatif. Selain itu, penomoran dilakukan secara acak. Sejumlah 30 butir pernyataan tersebut kemudian dilakukan validasi. Hasil validasi ini menyatakan bahwa terdapat 6 (enam) butir soal yang dinyatakan tidak valid menurut hasil analisis butir menggunakan besar V Aiken. Hasil tersebut dapat dilihat pada Tabel 7.

Tabel 7. Hasil V Aiken

\begin{tabular}{llllll}
\hline $\begin{array}{l}\text { No } \\
\text { Butir }\end{array}$ & Aiken V & $\begin{array}{l}\text { No } \\
\text { Butir }\end{array}$ & Aiken V & $\begin{array}{l}\text { No } \\
\text { Butir }\end{array}$ & Aiken V \\
\hline I & I,00 & II & 0,63 & $2 \mathrm{I}$ & $\mathrm{I}, 00$ \\
2 & $\mathrm{I}, 00$ & $\mathrm{I} 2$ & 0,75 & 22 & 0,75 \\
3 & $\mathrm{I}, 00$ & $\mathrm{I} 3$ & $\mathrm{I}, 00$ & 23 & $\mathrm{I}, 00$ \\
4 & $\mathrm{I}, 00$ & $\mathrm{I} 4$ & $\mathrm{I}, 00$ & 24 & 0,63 \\
5 & 0,75 & $\mathrm{I} 5$ & $\mathrm{I}, 00$ & 25 & $\mathrm{I}, 00$ \\
6 & $\mathrm{I}, 00$ & $\mathrm{I} 6$ & 0,75 & 26 & $\mathrm{I}, 00$ \\
7 & $\mathrm{I}, 00$ & $\mathrm{I} 7$ & $\mathrm{I}, 00$ & 27 & $\mathrm{I}, 00$ \\
8 & $\mathrm{I}, 00$ & $\mathrm{I} 8$ & $\mathrm{I}, 00$ & 28 & $\mathrm{I}, 00$ \\
9 & $\mathrm{I}, 00$ & $\mathrm{I} 9$ & $\mathrm{I}, 00$ & 29 & $\mathrm{I}, 00$ \\
$\mathrm{I0}$ & $\mathrm{I}, 00$ & 20 & $\mathrm{I}, 00$ & 30 & $\mathrm{I}, 00$ \\
\hline
\end{tabular}

Dengan jumlah ahli 4 (empat) orang, maka batas V Aiken yang digunakan adalah I,00. Jika besar V Aiken kurang dari itu dinyatakan tidak valid. Sebanyak 6 (enam) nomor yang tidak valid adalah butir nomor 5, II, I2, I6, 22, dan 24. Validasi ahli ini merupakan validasi secara konten. Validasi secara konten ini berdasarkan 
ahli yang mengerti mengenai pengukuran efikasi diri siswa (expert judgment). Hal ini sesuai dengan penelitian sebelumnya bahwa validasi konten dilakukan secara logis menurut ahli yang ada dan sesuai (Yang, 20II). Keenam butir yang dinyatakan tidak valid/gugur tersebut tidak digunakan untuk proses validasi empiris kepada siswa.

Proses validasi empiris dilakukan dengan siswa SMA sejumlah 300. Validasi empiris ini dilakukan di beberapa sekolah yang berbeda. Validasi empiris adalah validasi kedua yang berguna untuk menentukan butir mana yang tidak valid jika digunakan dalam pengukuran berdasarkan respons dari siswa. Hasil validasi empiris kemudian dianalisis menggunakan program dan menghasilkan reliabilitas dari satu alat ukur ( 24 butir) adalah 0,73 . Hal ini sesuai dengan penelitian sebelumnya bahwa besar reliabilitas yang diterima adalah dalam rentang 0,70 hingga 0,95 (Tavakol \& Dennick, 20II). Sedangkan besar validitas empiris untuk 24 butir pernyataan yang dinyatan dengan infit mean square dapat dilihat pada Tabel 8.

Tabel 8. Hasil Validasi Empiris

\begin{tabular}{|c|c|c|c|c|c|}
\hline $\begin{array}{l}\text { No } \\
\text { Butir }\end{array}$ & $\begin{array}{l}\text { Infit } \\
\text { MNSQ }\end{array}$ & $\begin{array}{l}\text { No } \\
\text { Butir }\end{array}$ & $\begin{array}{l}\text { Infit } \\
\text { MNSQ }\end{array}$ & $\begin{array}{l}\text { No } \\
\text { Butir }\end{array}$ & $\begin{array}{l}\text { Infit } \\
\text { MNSQ }\end{array}$ \\
\hline I & 0,99 & II & - & $2 \mathrm{I}$ & 0,83 \\
\hline 2 & 0,95 & 12 & - & 22 & - \\
\hline 3 & $0,9 \mathrm{I}$ & 13 & 0,82 & 23 & $0,9 \mathrm{I}$ \\
\hline 4 & $\mathrm{I}, \mathrm{OI}$ & 14 & 0,98 & 24 & - \\
\hline 5 & - & I5 & 0,90 & 25 & $\mathrm{I}, 07$ \\
\hline 6 & $\mathrm{I}, 08$ & 16 & - & 26 & 0,85 \\
\hline 7 & $\mathrm{I}, \mathrm{I} 2$ & I7 & 0,89 & 27 & $\mathrm{I}, 03$ \\
\hline 8 & $\mathrm{I}, 42$ & 18 & $\mathrm{I}, 33$ & 28 & 0,97 \\
\hline 9 & 0,90 & 19 & 0,90 & 29 & $\mathrm{I}, 02$ \\
\hline I0 & I,I 6 & 20 & 0,89 & 30 & 0,99 \\
\hline
\end{tabular}

Dari tabel tersebut, terdapat 2 butir soal yang memiliki besar infit mean square di luar rentang 0,77-I,30. Hal ini menyebabkan kedua butir pernyataan tersebut gugur dalam validasi empiris ini. Kedua butir tersebut adalah butir nomor 8 dan I8. Hasil dari validasi empiris ini adalah sebanyak 22 butir pernyataan dinyatakan valid dan reliabel serta dapat digunakan dalam proses pengukuran efikasi diri siswa SMA dalam belajar kimia.

\section{Penutup}

Berdasarkan hasil dan diskusi tersebut, dapat disimpulkan bahwa alat ukur efikasi diri telah dikembangkan dengan 6 (enam) aspek, yaitu pilihan aktivitas, usaha, ketekunan, belajar, pencapaian/prestasi, dan orientasi strategi. Sebanyak 30 butir pernyataan telah dikembangkan. Setelah melalui proses validasi, sebanyak 22 butir pernyataan dinyatakan valid dan reliabel untuk digunakan dalam pengukuran efikasi diri siswa.

Penelitian yang akan datang diharapkan dapat mengembangkan alat ukur siswa yang lain. Hal ini berguna untuk guru agar dapat mengetahui keadaan siswa yang diajar dalam proses pembelajaran. Selain itu, hasil pengukuran juga dapat digunakan untuk evaluasi pendidikan dalam skala kelas.

\section{Daftar Pustaka}

Aiken, L. R. (1985). Three coefficients for analyzing the reliability and validity of ratings. Educational and Psychological Measurement, 45(I), I3I-I42. https://doi.org/I0.II77/001316448545I0I2.

Arifin, Z. (2013). Konsep dan model pengembangan kurikulum. Remaja Rosdakarya. 
Baharudin, \& Wahyuni, E. N. (2009). Teori belajar dan pembelajaran. Ar-Ruzz Media.

Bandura, A. (1994). Self-Efficacy. In Encyclopedia of Human Behavior (Vol. 4, pp. 7I-8I). Academic Press.

Bandura, A. (1997). Self-Efficacy The Exercise of Control. W.H Freeman and Company.

Dinther, M. Van, Dochy, F., \& Segers, M. (20II). Factors affecting students' self-efficacy in higher education. Educational Research Review, 6(2), 95-I08. https://doi.org/I0.I0I6/j.edurev. 2010.10.003.

Kolo, A. G., Jaafa, W. M. B. W., \& Ahmad, N. B. (2017). Relationship between academic self-efficacy believed of college students and academic performance. IOSR Journal of Humanities and Social Science, 22(0I), 75-80. https://doi.org/I0.9790/0837-2201067580.

Kurbanoglu, N. I., \& Akim, A. (2010). The relationships between university students' chemistry laboratory anxiety, attitudes, and self-efficacy beliefs. Australian Journal of Teacher Education, 35(8), 48-59. https://doi.org/I0.I422I/ajte.2010v35n8.4.

Lawshe, C. H. (1975). A quantitative approach to content validity. Personnel Psychology, 28(I), 563-575.

Ormrod, J. E. (2003). Educational pyschology: developing learners (4th ed.). Pearson Education Inc.

Ornstein, A. C., \& Hunkins, F. P. (2009). Curriculum: foundations, principles, and issues (5th ed.). Pearson Education Inc.

Sadiman, A. S., Rahardjo, Haryono, A., \& Rahardjito. (1984). Media pendidikan: pengertian, pengembangan, dan pemanfaatannya. Rajawali.

Santrock, J. W. (20I I). Educational psychology (5th ed.). McGraw-Hill.

Sumintono, B., \& Widhiarso, W. (2015). Aplikasi pemodelan rasch: pada assessment pendidikan. Trim Komunikata.

Tavakol, M., \& Dennick, R. (20II). Making sense of Cronbach's alpha. International Journal of Medical Education, 2, 53-55. https://doi.org/I0.5I 16/ijme.4dfb.8dfd.

Trianto. (2009). Mendesain model pembelajaran inovatif progresif. Kencana.

Woolfolk, A. (2007). Educational psychology (IOth ed.). Pearson Education Inc.

Yang, W.-C. (20II). Applying Content Validity Coefficient and Homogeneity Reliability Coefficient to Investigate the Experiential Marketing Scale for Leisure Farms. Journal of Global Business Management, $7(\mathrm{I})$. http://www.jgbm.org/page/8 Wan-Chi Yang.pdf.

Zimmerman, B. J., Bandura, A., \& Martinez-pons, M. (I992). Self-motivation for academic attainment: the role of self-efficacy beliefs and personal goal setting. American Educational Research Journal, 29(3), 663-676. https://doi.org/I0.3102/00028312029003663. 